\title{
Novel Protective Properties of IGFBP-3 Result in Enhanced Pericyte Ensheathment, Reduced Microglial Activation, Increased Microglial Apoptosis, and Neuronal Protection after Ischemic Retinal Injury
}

\author{
Jennifer L. Kielczewski, ${ }^{*}$ Ping $\mathrm{Hu}{ }^{\dagger}$ \\ Lynn C. Shaw, ${ }^{*}$ Sergio Li Calzi, ${ }^{*}$ \\ Robert N. Mames, ${ }^{\ddagger}$ Tom A. Gardiner, ${ }^{\S}$ \\ Evan McFarland, ${ }^{\dagger}$ Tailoi Chan-Ling, ${ }^{\dagger}$ \\ and Maria B. Grant*
}

tic strategy for the treatment of ischemic vascular eye diseases, such as diabetic retinopathy and retinopathy of prematurity. (Am J Pathol 2011, 178:1517-1528; DOI: 10.1016/j.ajpath.2010.12.031)

Diabetic retinopathy is the leading cause of adult blindness, and retinopathy of prematurity is a leading cause of pediatric blindness. ${ }^{1-4}$ Insulin-like growth factor-1 (IGF-1) contributes to the pathogenesis of both conditions because unregulated levels of IGF-1 can lead to pathologic ocular neovascularization. ${ }^{5-8}$ The effects of IGF-1 are mediated by the IGF-1 receptor and are modulated by complex interactions with six different IGF binding proteins (IGFBPs), which function as transporter proteins and as storage pools for IGF-1 in tissues. Of the six different IGFBPs, IGFBP-3 is the most abundant, carrying more than $75 \%$ of serum IGF-1 and IGF-2 in heterotrimeric complexes. ${ }^{9,10}$ The IGFBP-3 has autocrine and paracrine actions that affect cell mobility and survival, and it is regulated by hypoxia. ${ }^{10}$ Depending on the cellular milieu and local levels, IGFBP-3 can be either proangiogenic or antiangiogenic. ${ }^{11}$ Abnormally low levels of IGFBP-3 occur in the serum of low-birth-weight infants, and normalization of these levels is being considered as a strategy to prevent the development of retinopathy of prematurity. ${ }^{12}$

Previously, we showed that IGFBP-3 facilitates remodeling of the retinal vasculature after ischemic injury in the oxygen-induced retinopathy (OIR) model. ${ }^{13,14}$ Under con-

Supported by the NIH (grants R01 EY07739, R01 EY12601, and R01 EY 018358 to M.B.G.); the National Health and Medical Research Council of Australia (grant 571100 to T.C.-L.); the Australian Government Department of Innovation, Industry, Science, and Research International Science Linkages Program (grant CG130097 to T.C.-L.); and the Rebecca L. Cooper Medical Research Foundation (T.C.-L.).

T.C.-L. and M.B.G. contributed equally to this work.

Accepted for publication December 22, 2010.

Address reprint requests to Maria B. Grant, M.D., Department of Pharmacology and Therapeutics, University of Florida, Gainesville, FL 326100267. E-mail: grantma@ufl.edu. 
ditions of hypoxia, IGFBP-3 expression by ischemic tissue can stimulate hematopoietic stem cell (HSC) migration, thus promoting the recruitment of these cells from the circulation into areas of ischemia, where they contribute to endothelial repair. ${ }^{13,15}$ Lofqvist et al ${ }^{12}$ showed that IGFBP-3-deficient mice have increased retinal vessel loss when subjected to the OIR model compared with wild-type mice. We demonstrated that IGFBP-3 increases recruitment of green fluorescent protein-positive $\left(\mathrm{GFP}^{+}\right)$bone marrow-derived HSCs into the injured retina, and we found that the recruitment and migratory effects of IGFBP-3 in the endothelium are nitric oxide mediated. ${ }^{14}$ In addition, we found that IGFBP-3 decreases apoptosis of endothelial cells in ischemic retinal vessels. Although IGFBP-3 demonstrates beneficial effects in restoring healthy endothelium after injury, ${ }^{12-14}$ a paucity of information exists regarding the effect of IGFBP-3 on supporting cells of the vasculature (specifically, pericytes and microglia) and neurons. To address this issue, we undertook the present study to assess the cytoprotective effects of IGFBP-3 and found that IGFBP-3 demonstrates neuroprotective, antiapoptotic, and anti-inflammatory effects after retinal injury.

\section{Materials and Methods}

\section{Animals}

All the animals were treated in accordance with the Guiding Principles in the Care and Use of Animals $(\mathrm{NIH})$ and the Association for Research in Vision and Ophthalmology Statement for the Use of Animals in Ophthalmic and Vision Research. C57BL/6J.gfp transgenic mice homozygous for $\mathrm{GFP}^{+}$were obtained from The Jackson Laboratory (Bar Harbor, ME) and were housed and bred in the institutional animal care facilities at the University of Florida. Eighteen adult chimeric mice were used for immunohistochemical studies. Pregnant C57BL/6 mice were purchased from The Jackson Laboratory. We used 32 mouse pups for transmission electron microscopy experiments, terminal deoxynucleotidyl transferase-mediated dUTP nick-end labeling (TUNEL), and immunohistochemical analysis.

\section{$\mathrm{GFP}^{+}$Chimeric Mice}

The $\mathrm{GFP}^{+}$chimeric mice were generated as previously reported. ${ }^{16}$ Briefly, to generate the C57BL/6J.gfp chimeric mice, femoral and tibial bone marrow were harvested from $\mathrm{GFP}^{+}$transgenic (homozygous) male mice. Antibodies to c-kit (CD117) and Sca-1 (both from BD Pharmingen, San Diego, CA) were used to isolate a select population of undifferentiated bone marrow cells. These cells were then separated using flow cytometry (FACSCalibur flow cytometer; BD Biosciences, San Jose, CA) to obtain a population of cells that was $\mathrm{GFP}^{+} / \mathrm{c}-\mathrm{kit}^{+} / \mathrm{Sca}-1^{+}$. The purity of the $\mathrm{GFP}^{+} /$ $\mathrm{c}-\mathrm{Kit}^{+} / \mathrm{Sca}-1^{+}$cell population obtained from fluorescenceactivated cell sorting typically resulted in a 95\% hemangioblast population. These cells were then injected into the retro-orbital sinuses of lethally irradiated ( 9.5 Gy from a $\mathrm{Cs}^{137}$ source) 6- to 8-week-old adult female mice. After 3 months, GFP ${ }^{+}$cell engraftment was confirmed by flow cytometric analysis of mouse peripheral blood as previously described. ${ }^{17,18}$ Mice with a $\mathrm{GFP}^{+}$engraftment greater than $80 \%$ were used for experimentation.

\section{Laser Photocoagulation Injury Model}

Three groups of animals were used in the experiments, all consisting of C57BL/6J. gfp chimeric mice: laser only ( $n=$ $6)$, laser with IGFBP-3 injection $(n=6)$, and IGFBP-3 injection only $(n=6)$. Mice were anesthetized with ketamine and xylazine before laser treatment. Animals were photocoagulated by delivering 35 spots at $150 \mathrm{~W}$ for 1.0 second with an argon green laser to the retinal vessels of the right eye at a distance of 1 disk diameter from the optic nerve head. This laser injury model has been used previously. ${ }^{14,16}$ Retinal vessels were occluded in an attempt to cause ischemia: laser applications were applied repeatedly to the same point on the vessel, as needed, to whiten the area of treatment and damage the vasculature.

A total of $2 \mu \mathrm{L}$ of IGFBP-3 plasmid $(2 \mu \mathrm{g} / \mu \mathrm{L})$, under the control of a proliferating endothelial cell-specific promoter $\left(E T_{e}\right)$ composed of a $7 \times 46$-mer multimerized endothelin enhancer upstream of a human Cdc6 promoter, ${ }^{19}$ was placed into liposomes and was injected intravitreally into the right eye of the 12 adult female mice, as noted previously herein. All three groups of mice were sacrificed 3 weeks after laser and/or IGFBP-3 treatment.

\section{OIR Model}

We used the mouse model of OIR developed by Smith et al. ${ }^{20}$ Mice were injected intravitreally with a plasmid expressing mouse IGFBP-3 $(2 \mu \mathrm{g} / \mu \mathrm{L})$ under the control of the proliferating endothelial cell-specific promoter or an "empty" cloning vector at postnatal day (P) 1 in a volume of $0.5 \mu \mathrm{L}$ per eye. By using a proliferating endothelial cell-specific promoter, IGFBP-3 expression was targeted to areas of neovascularization as previously described..$^{19}$ At $P 7$, the pups were placed into high oxygen (75\%) for 5 days and then were subsequently returned to room air at P12. The animals were euthanized immediately on removal from hyperoxia at $\mathrm{P} 12$ or 5 days after returning to room air at P17. Eyes from mice injected with plasmid expressing IGFBP-3 $(n=16)$ were compared with those from mice injected with empty cloning vector $(n=16)$ and/or the uninjected eye of the same animal.

\section{Transmission Electron Microscopy of OIR Mouse Retinas}

The IGFBP-3-injected eyes $(n=6)$ and the contralateral uninjected control eyes $(n=6)$ of mouse pups at P12 and P17 were enucleated and immersion fixed in $2.5 \%$ glutaraldehyde in $0.1 \mathrm{M}$ cacodylate at $\mathrm{pH} 7.2$ with $10 \mathrm{mmol} / \mathrm{L}$ $\mathrm{MgCl}_{2}$ (Electron Microscopy Sciences, Hatfield, PA) for 1 hour at room temperature. Whole eye globes were then washed with PBS. Tissue blocks were treated with $1 \%$ osmium tetroxide, dehydrated in ethanol, and embedded in Spurr's resin as previously reported. ${ }^{21}$ 
Immunofluorescence Histochemical Analysis in

\section{Adult Chimeric Mice}

Mice were euthanized by anesthetizing them with isoflurane followed by cervical dislocation. Eyes were enucleated and fixed with 4\% paraformaldehyde/PBS for 1 hour The neural retina was dissected from the posterior cup and was washed with PBS. Neural retinas were stained as previously reported for detection of NG2 (Chemicon International, Temecula, CA) for pericytes and S-100 (Sigma-Aldrich, St. Louis, MO) for detection of astrocytes and their somas to covisualize $\mathrm{GFP}^{+}$cells in the vasculature of flat-mounted retinas. ${ }^{22,23}$ Retinas were imaged via confocal microscopy using a Leica argon krypton laser mounted on a Leica DMRBE epifluorescence photomicroscope using Leica imaging software (Leica Micro- systems $\mathrm{GmbH}$, Wetzlar, Germany). Fluorescence microscopy was also performed using OpenLab 4.0 imaging software (Weltham, MA). Images were processed using Adobe Photoshop 5.0 software (Adobe Systems Inc., San Jose, CA).

\section{Immunofluoresence Histochemical Analysis for the OIR Model}

Astrocytes [S-100 or glial fibrillary acidic protein (GFAP)], ${ }^{22}$ pericytes (NG2), ${ }^{24}$ and endothelial cells and microglia (both stained for GS isolectin B4) ${ }^{25-28}$ were visualized using triple-marker immunohistochemical analysis on retinal whole mounts and cryosections in the midperipheral and peripheral regions of the retina. Retinas of OIR animals were examined using a confocal microscope
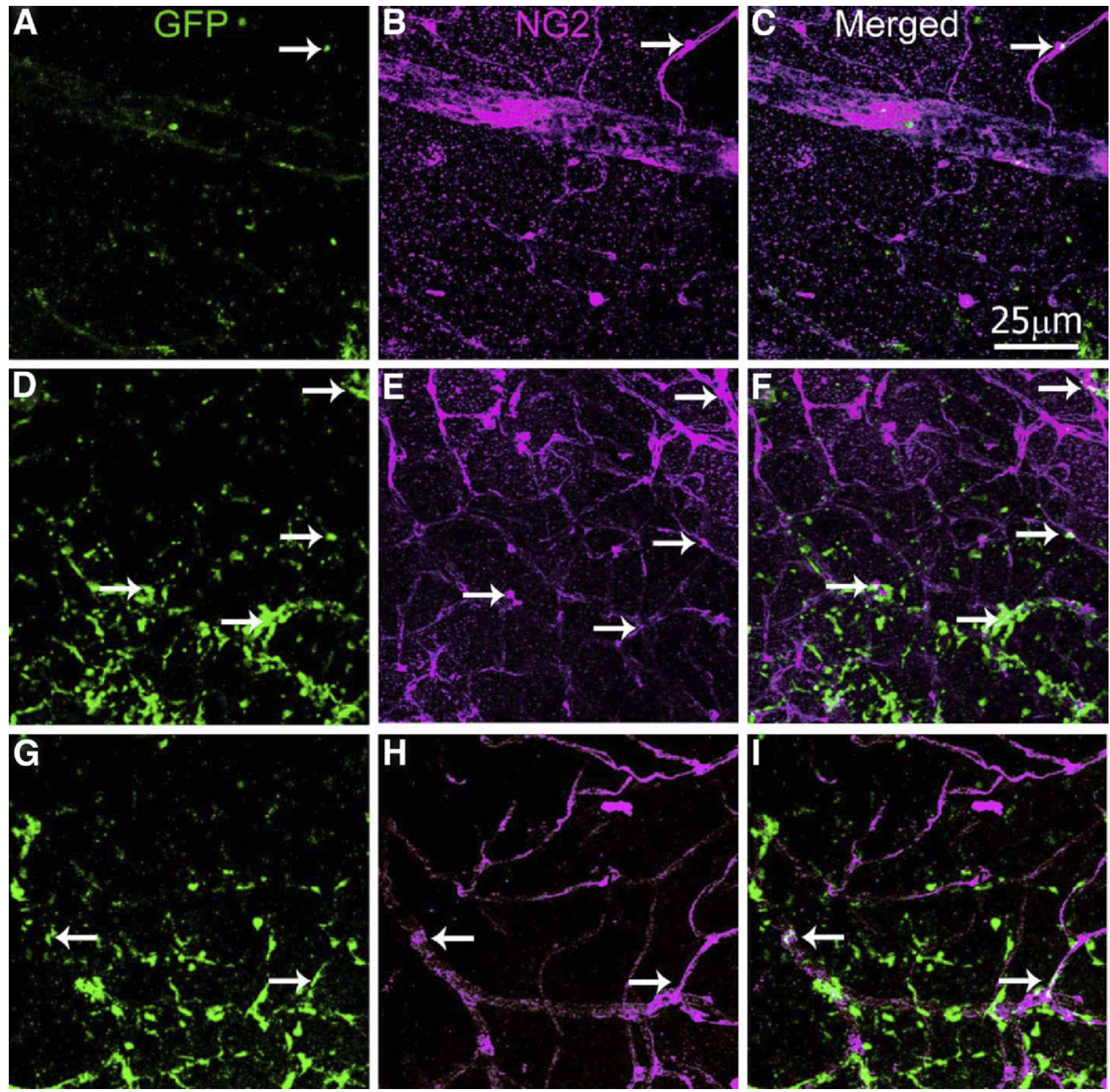

Figure 1. Overexpression of IGFBP-3 by vascular endothelial cells promotes GFP ${ }^{+}$HSC differentiation into pericytes in an adult ocular laser model. A-I: The green stain represents $\mathrm{GFP}^{+}$cells, and the purple stain represents NG2 for the detection of pericytes. A-C: Representative images from mouse retinas subjected to laser-only retinal vessel injury showing very few $\mathrm{GFP}^{+}$cells giving rise to $\mathrm{NG}^{+}$pericytes (white arrows). D-F: Retinas from mice that were injected with IGFBP-3-expressing plasmid and that also underwent laser injury showing increased numbers of $\mathrm{GFP}^{+}$cells differentiating into NG2 ${ }^{+}$pericytes (white arrows). G-I: Retinas from mice injected with IGFBP-3-expressing plasmid showing $\mathrm{GFP}^{+}$cells differentiating into $\mathrm{NG}^{+}$pericytes (white arrows). The scale bar in $\mathbf{C}$ is applied throughout $\mathbf{A}-\mathbf{I}$ 
(Zeiss LSM 510 META; Carl Zeiss Microlmaging GmbH, Jena, Germany). Images were processed using Adobe Photoshop CS software (Adobe Systems Inc.).

\section{Evaluation of Pericyte, Astrocyte, Microglial, and} Neuronal Cell Death in the OIR Model

Retinas were examined after exposure to a high-oxygen environment (P12) and after 5 days' return to room air (P17). Pericyte, astrocyte, microglial, and neuronal cell death were assessed using TUNEL ( $F$. Hoffman-La Roche, Basel, Switzerland) on retinal whole mounts and transverse sections. Oxygen-induced retinopathy animals were stained with an in situ cell death detection system based on the TUNEL method ${ }^{29}$ to label nuclei undergoing DNA fragmentation, followed by GS isolectin B4 for vascular endothelial cells and activated microglia (Sigma-Aldrich), NG2 for pericytes (Chemicon International), OX42 for macrophages (Serotec, Oxford, United Kingdom), and NeuN or $\beta$ III tubulin for neurons (Chemicon International).

\section{Statistical Analysis of Pericyte, Astrocyte, Microglial, and Neuronal Cell Death in the OIR Model}

Representative fields of view (area $=0.0625 \mathrm{~mm}^{2}$ ) from the midperipheral and peripheral retinas were counted using a $\times 40$ objective as the field of view for analysis. In each field of view, TUNEL ${ }^{+} /$GS lectin $^{+}$vascular endothe-
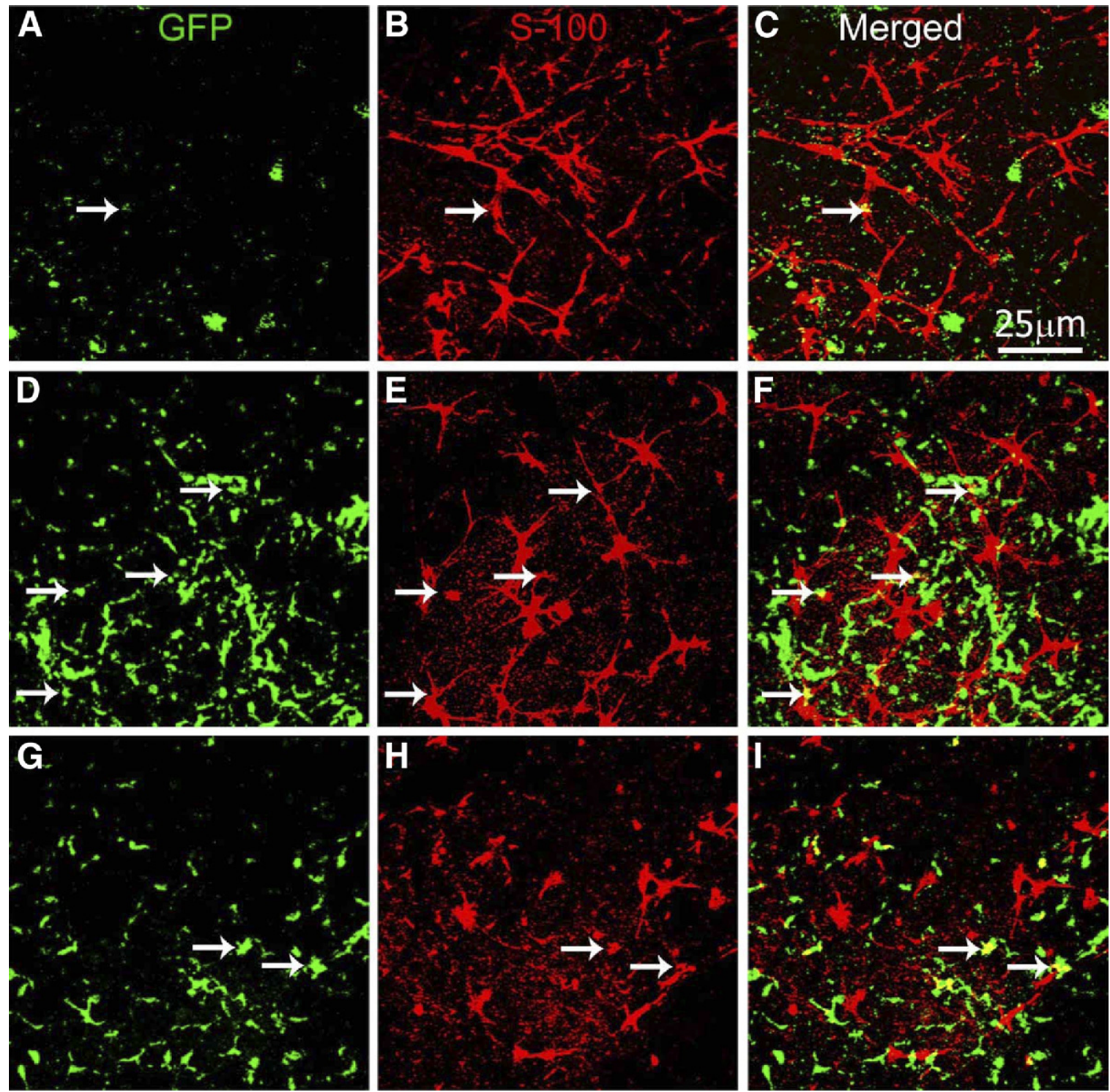

Figure 2. Overexpression of IGFBP-3 by vascular endothelial cells results in GFP ${ }^{+}$HSC differentiation into astrocytes in an adult ocular laser model. A-I: The green stain represents $\mathrm{GFP}^{+}$cells, and the red stain represents S-100 for the detection of astrocytes. A-C: Laser-only retinas showing S-100 immunoreactivity. GFP ${ }^{+}$ HSC differentiated into S- $100^{+}$astrocytes (white arrows) in very low numbers in the laser-only eyes. D-F: Overexpression of IGFBP-3 + laser retinal injury showing markedly increased S-100 immunoreactivity. The $\mathrm{GFP}^{+}$HSCs gave rise to S- $100^{+}$astrocytes (white arrows) that were more evident in laser + IGFBP-3-overexpressing eyes compared with laser-only eyes. G-I: The IGFBP-3-overexpressing eyes showing GFP $^{+}$cell differentiation into S-100 $^{+}$astrocytes (white arrows). The scale bar in $\mathbf{C}$ is applied throughout $\mathbf{A}-\mathbf{I}$ 
SUPERFICIAL

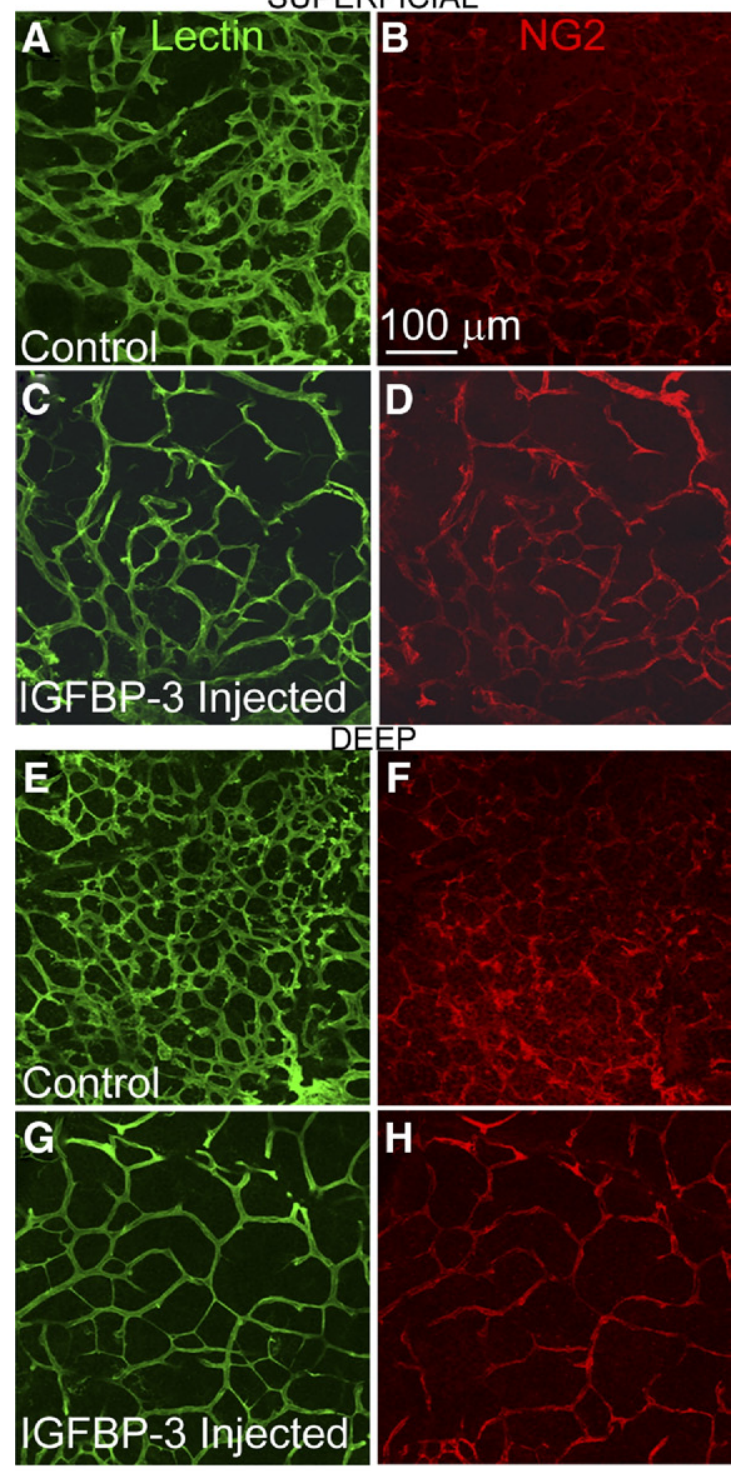

I

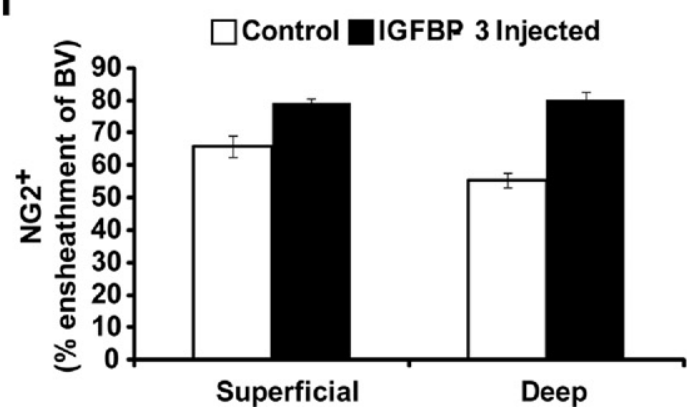

Figure 3. The IGFBP-3 enhances pericyte ensheathment and normalizes vessel morphology during the hypoxic phase of OIR. A-H: Retinal whole mounts in the peripheral region of the retina at $\times 20$ magnification, double-labeled with GS lectin (endothelial cells, green) and NG2 (pericytes, red) in IGFBP-3-overexpressing eyes ( $\mathbf{C}$ and $\mathbf{D}$, superficial plexus; $\mathbf{G}$ and $\mathbf{H}$, deep plexus) and contralateral control uninjected eyes (A and $\mathbf{B}$, superficial plexus; $\mathbf{E}$ and $\mathbf{F}$, deep plexus). Eyes overexpressing IGFBP-3 showed a higher incidence of $\mathrm{NG}^{+}$pericyte ensheathment $(\mathbf{C}$ and $\mathbf{D}$ and $\mathbf{G}$ and $\mathbf{H}$ versus $\mathbf{A}$ and $\mathbf{B}$ and $\mathbf{E}$ and $\mathbf{F}$, respectively) and displayed normal vessel morphology compared with contralateral control uninjected eyes. I: Quantitative analysis of pericyte ensheathment showed that IGFBP-3-overexpressing eyes had a significantly higher mean incidence of $\mathrm{NG}^{+}$pericyte ensheathment than did blood vessels (BVs) in contralateral control uninjected eyes $\left({ }^{* * *} P<0.05\right)$. Error bars represent SE. The scale bar in $\mathbf{B}$ is applied throughout $\mathbf{A}-\mathbf{H}$ lial cells, TUNEL ${ }^{+} / \mathrm{NG}^{+}$pericytes, $\mathrm{TUNEL}^{+} / \mathrm{S}-100^{+}$astrocytes, and $\mathrm{TUNEL}^{+} / \mathrm{NeuN}^{+}$neurons were counted, as previously described in Chan-Ling $\mathrm{T}$ et al. ${ }^{30}$ Data are reported as mean $\pm \mathrm{SE}$, with $n=4$ per experimental group.

\section{Quantification of NG2 Pericyte Ensheathment}

The frequency of NG2 pericyte ensheathment of retinal vessels was determined using a modified method previously described for determining the desmin ensheathment ratio. ${ }^{31}$ Four representative fields of view from the midperipheral retina were counted using a $\times 40$ objective as the field of view for analysis. Each confocal image was overlaid with a $23 \times 23$ equally spaced grid using Adobe Photoshop CS. The grid was superimposed onto each image. The occurrence of NG2 labeling relative to lectin labeling at the 529 intersection points yielded the percentage of pericyte ensheathment.

\section{Quantification of Microglia}

After visualization of the vessels and activated microglia with GS isolectin B4, four fields of views were captured using a $\times 40$ objective, and the number of microglia was determined in each field of view. The average number of cells counted per field of view (area $=0.0625 \mathrm{~mm}^{2}$ ) was multiplied by 16 to obtain the number of cells per square millimeter.

\section{Statistical Analysis}

$T$-tests were performed. Differences were considered to be statistically significant at $P<0.05$.

\section{Results \\ IGFBP-3 Promotes Differentiation of Bone Marrow-Derived Progenitors into Pericytes and Astrocytes}

The contribution of bone marrow-derived cells to vascular repair has been well appreciated regarding their ability to repair endothelium. We previously showed that IGFBP-3 can promote differentiation of HSCs into endothelial cells after laser-induced mouse retinal injury. ${ }^{14}$ Less well understood is the ability of these cells to become perivascular cells, such as pericytes and astrocytes; however, their plasticity is generally believed to remain context and injury determined. ${ }^{32-36}$ To address this issue, we generated $\mathrm{GFP}^{+}$chimeric mice and laser injured their retinal vessels. Immediately after laser injury, IGFBP-3-expressing plasmid was injected into the vitreous. Three weeks after injury, retinas from mice injected with the IGFBP-3 plasmid demonstrated increased incorporation of $\mathrm{GFP}^{+}$cells into the retinal vasculature in the absence or presence of laser injury (Figures 1 and 2, D-I). The GFP ${ }^{+}$cells differentiated into pericytes (Figure 1) and astrocytes (Figure 2) as determined by immunohistochemical analysis. Although not quantified, IGFBP-3-injected, laser-treated retinas showed 
a striking increase in $\mathrm{GFP}^{+}$cell differentiation into pericytes (NG2) and astrocytes (S-100) compared with the laseronly-treated retinas (Figures 1 and 2, D-F versus A-C). Previously, we showed that IGFBP-3 increases astrocytic ensheathment in the OIR model, ${ }^{14}$ and this is consistent with the present study, which shows IGFBP-3-mediated HSC differentiation into astrocytes, which, in turn, would promote astrocytic ensheathment.

\section{IGFBP-3 Increases Pericyte Ensheathment and} Decreases Pericyte Apoptosis in OIR Mice

Because we observed that IGFBP-3 injection can increase bone marrow-derived progenitor cell differentia- tion into pericytes in the OIR model, we asked whether IGFBP-3 could affect pericyte morphology and apoptosis in newly forming vessels. The developing mouse vasculature is in a state of constant cell turnover. Hence, it is an ideal model for studying apoptosis and cellular remodeling. Compared with contralateral uninjected eyes, IGFBP-3-injected eyes showed pericytes with significantly greater NG2 immunoreactivity and NG2 ensheathment in the superficial and outer plexus (Figure 3, A, B, E, and $F$ versus $C, D, G$, and $H$ ). Quantification of the frequency of pericyte ensheathment revealed that NG2 pericyte ensheathment of retinal vasculature was significantly increased in P17 IGFBP-3-injected eyes (mean \pm SE: 79 \pm 1.18 in superficial plexus and $80.25 \pm 2.52$ in deep
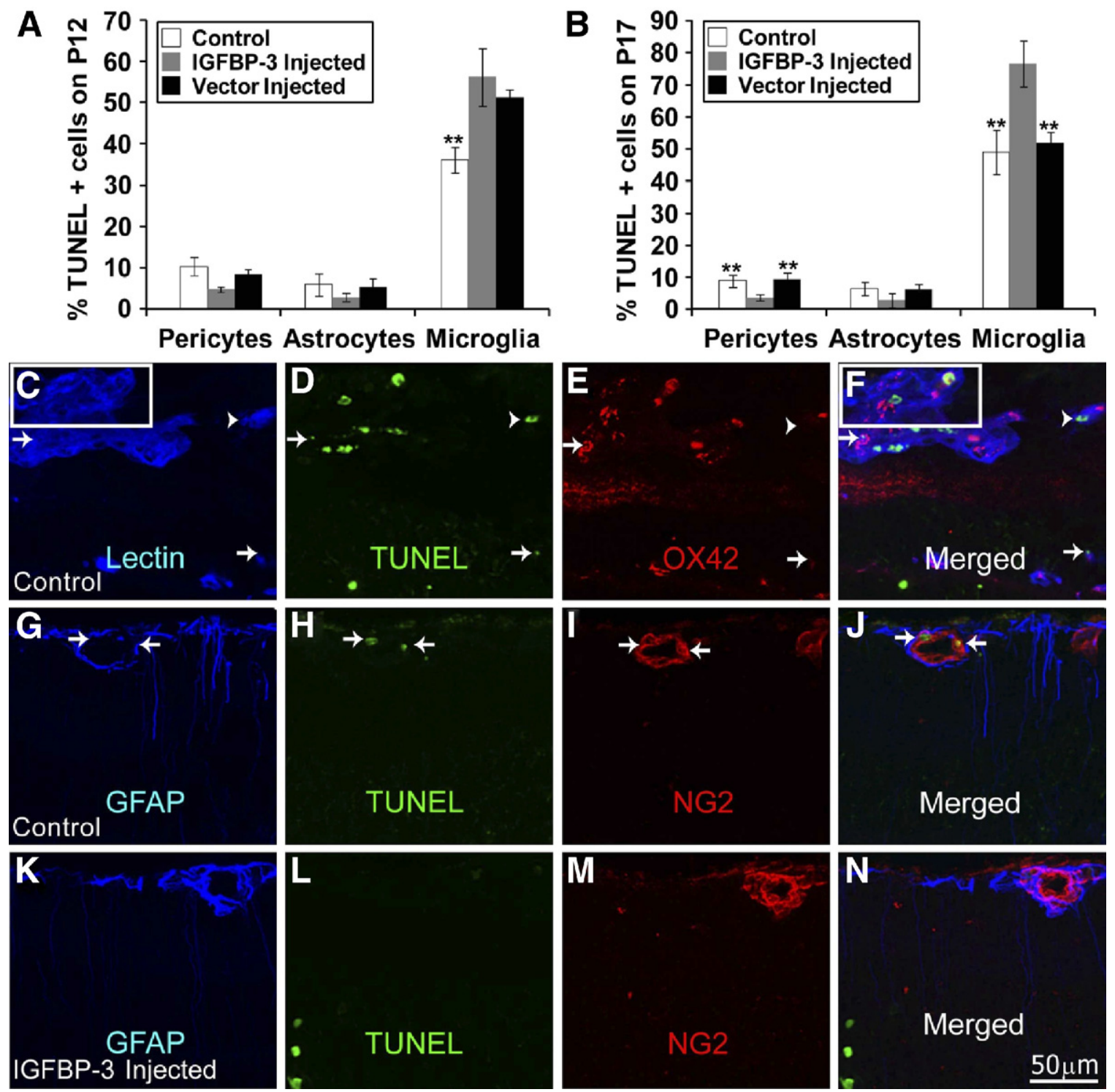

Figure 4. Overexpression of IGFBP-3 increases microglial/macrophage apoptosis during the hyperoxia (P12) and hypoxic (P17) phases in the OIR model Overexpression of IGFBP-3 resulted in a marked increase in mean microglial/macrophage apoptosis, which was significant at P12 (A) and P17 (B) $(* * P<0.05)$ Overexpression of IGFBP-3 reduced the level of apoptotic death observed in pericytes at P17 (** $P<0.05)$. Error bars represent SE. C-N: Retinal sections triple-labeled with GS isolectin/GFAP, TUNEL, and OX42/NG2 at P17 in the OIR model. C-F: Large numbers of GS lectin ${ }^{+} / \mathrm{OX}_{4} 2^{+} / \mathrm{TUNEL}^{+}$apoptotic macrophages/microglia (arrows) are observed. In addition, a population of cells represented GS lectin ${ }^{+} / \mathrm{TUNEL}^{+}$apoptotic activated microglia (arrowheads). Preretinal vessels were evident in control eyes (see the insets in $\mathbf{C}$ and $\mathbf{F}$ ) but less so in IGFBP-3-overexpressing eyes. G-N: A higher number of NG2 ${ }^{+} /$TUNEL $^{+}$ apoptotic pericytes (two arrows) is observed in controls $(\mathbf{G}-\mathbf{J})$. As a result of a higher incidence of pericyte death, the thickness of $\mathrm{NG}^{+}{ }^{+}$pericyte and $\mathrm{GFAP}^{+}$ astrocytic ensheathment observed in the contralateral control uninjected eyes were markedly reduced. The scale bar in $\mathbf{N}$ is applied throughout $\mathbf{A}-\mathbf{N}$. 
plexus) compared with in contralateral uninjected eyes (mean \pm SE: $65.83 \pm 3.32$ in superficial plexus and $55.33 \pm 2.31$ in deep plexus; $P<0.05$; Figure 3 I). Furthermore, IGFBP-3-injected eyes demonstrated marked normalization in vessel morphology compared with contralateral uninjected eyes. This normalization of vessel morphology induced a more regular bifurcation of the vascular tree, less variation in vessel caliber, and fewer preretinal vessels (Figure 3, C-D and $\mathrm{G}-\mathrm{H}$ ). The latter finding is in agreement with previous findings showing that IGFBP-3 reduces preretinal neovascularization. ${ }^{13}$

At P17 in the OIR model, the IGFBP-3 plasmid reduced pericyte apoptosis in the ischemic mouse retina compared with in the contralateral uninjected and control vector-injected eyes, where a higher mean \pm SE number of $\mathrm{NG}^{+} / \mathrm{TUNEL}^{+}$apoptotic pericytes were observed (3.82 \pm 0.81 versus $8.96 \pm 1.89$ and $9.41 \pm 2.17$, respectively; $P<0.05$; Figure 4B and $\mathrm{G}-\mathrm{J}$ ). Our observation of a higher incidence of pericyte death in the contralateral uninjected eyes suggests that in the absence of IGFBP-3, a higher amount of pericyte cell death exists, resulting in a thinner layer of $\mathrm{NG}_{2}^{+}$pericytic and $\mathrm{GFAP}^{+}$ astrocytic ensheathment of retinal blood vessels (Figure 4, G-J compared with $\mathrm{K}-\mathrm{N}$ ). Thus, these data suggest that IGFBP-3 can protect retinal pericytes and astrocytes from apoptotic cell death, resulting in greater pericyte and astrocyte ensheathment.

\section{IGFBP-3 Increases Microglia Apoptosis and Reduces Activated Microglia in the Hypoxic Phase of the OIR Model}

Exposure to the IGFBP-3 plasmid led to a marked increase in GS lectin ${ }^{+}$microglial death at P12 (mean \pm SE: $56.25 \pm 6.97$ ) versus non-IGFBP-3-injected eyes (mean \pm SE: $36.06 \pm 3.12$ ) or the control vector-injected eyes (mean \pm SE: $51.34 \pm 1.90 ; P<0.05$; Figure 4A). This is also the case at P17, where IGFBP-3-injected eyes exhibit significantly increased microglial cell apoptosis (mean \pm SE: $76.64 \pm 7.13$ ) versus the contralateral uninjected eyes (mean \pm SE: $48.97 \pm 6.85$ ) and control vector-injected eyes (mean \pm SE: $52.06 \pm 3.12 ; P<$ 0.05; Figure 4B). We also confirmed this finding using

\section{SUPERFICIAL}
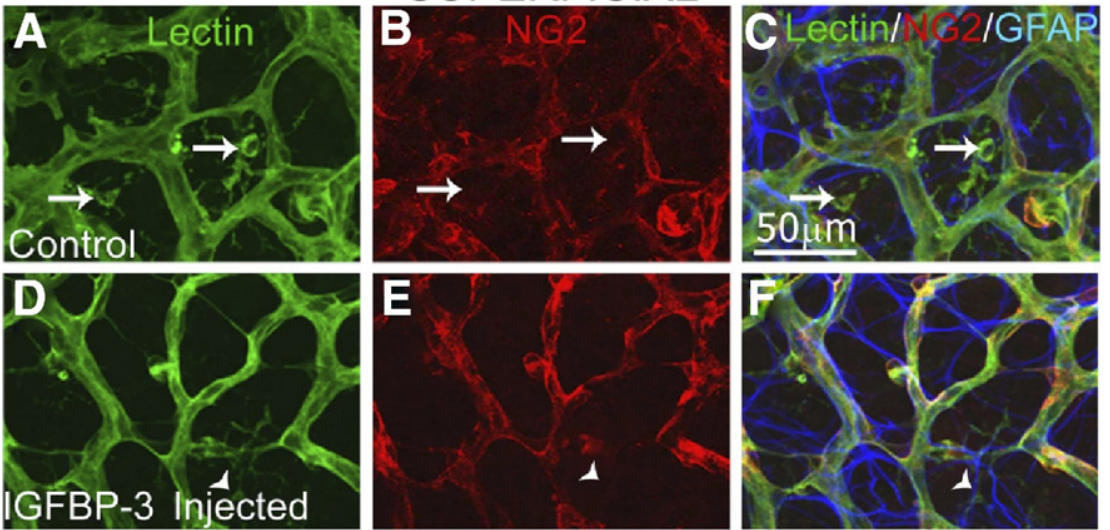

DEEP
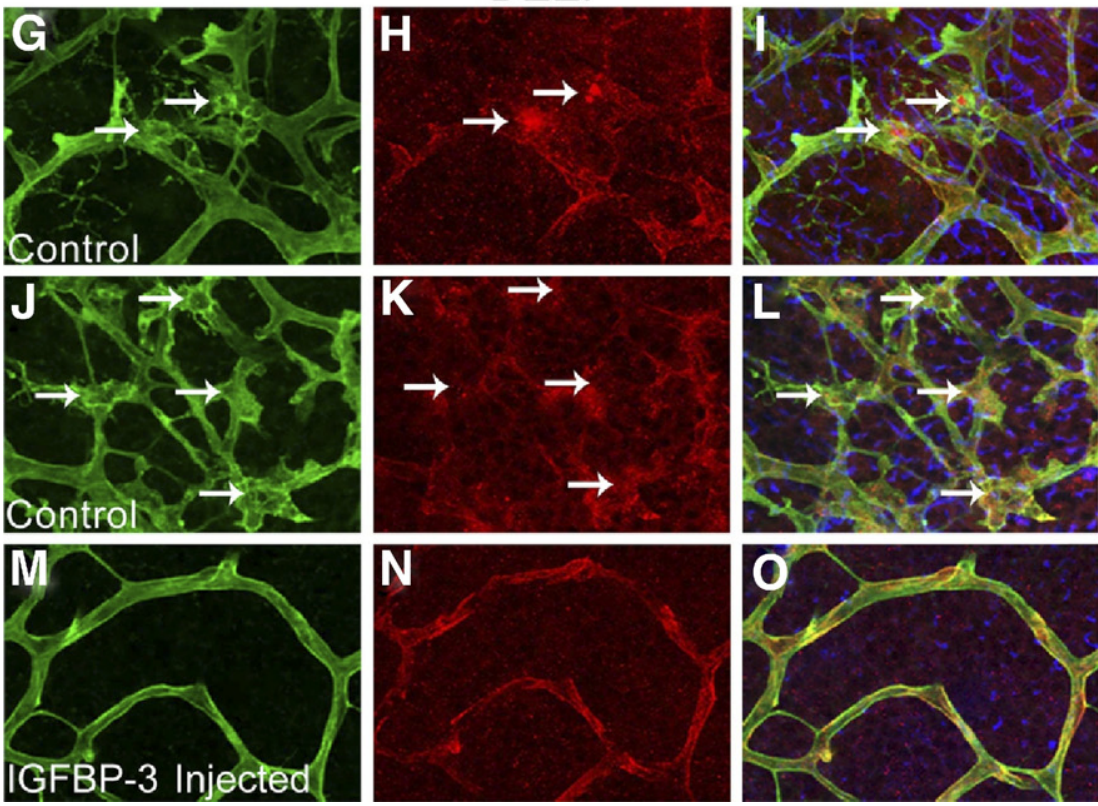

Figure 5. Overexpression of IGFBP-3 reduces microglial activation. A-O: Retinal whole mounts in the peripheral region of the retina at $\times 40$ magnification, triple-labeled with GS isolectin B4 (green) NG2 (red), and GFAP (blue) in the superficial and deep retinal plexus at P17. During the hypoxic neovascularization of OIR, marked microglial activation was evident, as indicated by strong expression of GS lectin and a change in microglial morphology from that of resting microglia (arrowheads in D-F) to that of activated microglia with enlargement of the soma and thickening and shortening of the processes (arrows in A-C and G-L). These microglial cells surround $\mathrm{NG}^{+}$debris, suggesting that these activated microglia are actively taking up apoptotic pericytes in the deep vascular plexus in contralateral control eyes (G-I) In $\mathbf{J}-\mathbf{L}$, another region is observed, possibly at later stage of the apoptotic process, where $\mathrm{NG}^{+}$ debris is punctate and digestion by the four microglia in the field of view (indicated by arrows) is markedly more advanced and the microglial morphology has changed to an amoeboid form. P: The mean density of microglia was found to be significantly lower in IGFBP-3-overexpressing eyes than in contralateral control eyes $\left({ }^{* *} P<0.05\right)$. Error bars represent SE. Overexpression of IGFBP-3 prevented up-regulation of GFAP expression in Müller glia ( $\mathbf{O}$ versus $\mathbf{I}$ and $\mathbf{L}$ ). The scale bar in $\mathbf{C}$ is applied throughout $\mathbf{A}-\mathbf{O}$.

\section{$\mathbf{P}$}

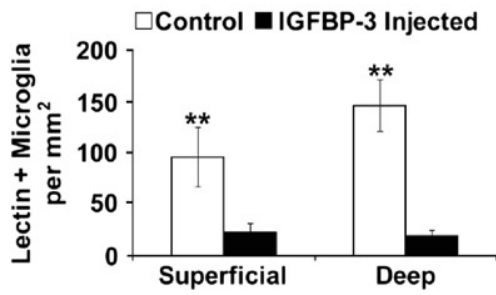


retinal cross sections, in which we observed a significant increase in apoptosis in IGFBP-3-injected eyes (mean \pm SE: $58 \pm 13.5)$ compared with uninjected control eyes (mean \pm SE: $17.8 \pm 13.8 ; P<0.05$ ).

To further identify the TUNEL-positive cells as belonging to the macrophage/microglial lineage, OX42 (a macrophage-specific marker) was used. Most of the cells were GS lectin ${ }^{+}$or $\mathrm{OX} 42^{+} / \mathrm{GS}$ lectin ${ }^{+}$, with only a few $\mathrm{OX} 42^{+}$macrophages that were not labeled by GS isolectin B4 (Figure 4, C-F).

The OIR model is known to induce inflammation, resulting in many activated microglial cells. ${ }^{37}$ Thus, we next evaluated whether IGFBP-3 could mediate cytoprotection after injury by reducing the number of activated microglial cells. Retinas of mice injected with IGFBP-3 showed a significantly reduced number of activated microglial cells during the hypoxic phase of the OIR model compared with the noninjected eyes (Figure 5, A-O). We performed a quantitative analysis of the density of microglial cells at the level of focus coinciding with the superficial and deep vascular plexus. The IGFBP-3 was found to reduce the mean \pm SE density of activated microglial cells in both layers [22.68 $\pm 8.31 / \mathrm{mm}^{2}$ (IGFBP-3-injected eye) versus $95.64 \pm 28.69 / \mathrm{mm}^{2}$ (contralateral uninjected control eye) in the superficial layer and $19.00 \pm 5.31 / \mathrm{mm}^{2}$ (IGFBP-3-injected eye) versus $146.00 \pm 25.33 / \mathrm{mm}^{2}$ (contralateral uninjected control eye) in the deep layer] (Figure 5P). The findings of increased microglial cell apoptosis and reduced density of activated microglial cells are suggestive of an anti-inflammatory role of IGFBP-3. In a healthy young adult mouse retina, Müller glia do not express immunohistochemically detectable levels of GFAP. However, during the hypoxic phase of OIR, Müller cells in the retina expressed high levels of GFAP (Figure 5, A-C and $G-L)$, which was consistent with that observed by Kramerov et al. ${ }^{38}$ Levels of GFAP expression were reduced in the IGFBP-3-injected eye (Figure 5, M-O), suggesting that IGFBP-3 can reduce GFAP expression by Müller cells. The findings of increased microglial cell apoptosis and a reduced number of activated microglial cells imply that IGFBP-3 can act as an anti-inflammatory factor in the ischemic mouse retina.

\section{IGFBP-3 Protects Retinal Neurons from Apoptosis in the OIR Model}

The extent of neuronal cell death was assessed using transmission electron microscopy (Figure 6) and TUNEL analysis (Figure 7). The IGFBP-3-injected OIR mice showed reduced neuronal cell death in retinal cross sections compared with uninjected control OIR mice. Increased numbers of apoptotic cells were observed in control uninjected mice (Figure 6, A and C) compared with in IGFBP-3-injected mice (Figure 6, B and D) at P12 and P17. Electron microscopy confirmed that the intensely stained cells and subcellular fragments observed in toluidine blue-stained resin sections were, in fact, cells undergoing apoptosis (Figure 6, F-H). Such cells showed the "dark cell" change typical of early apoptosis in neurons followed by nuclear and cytoplasmic cleavage. In
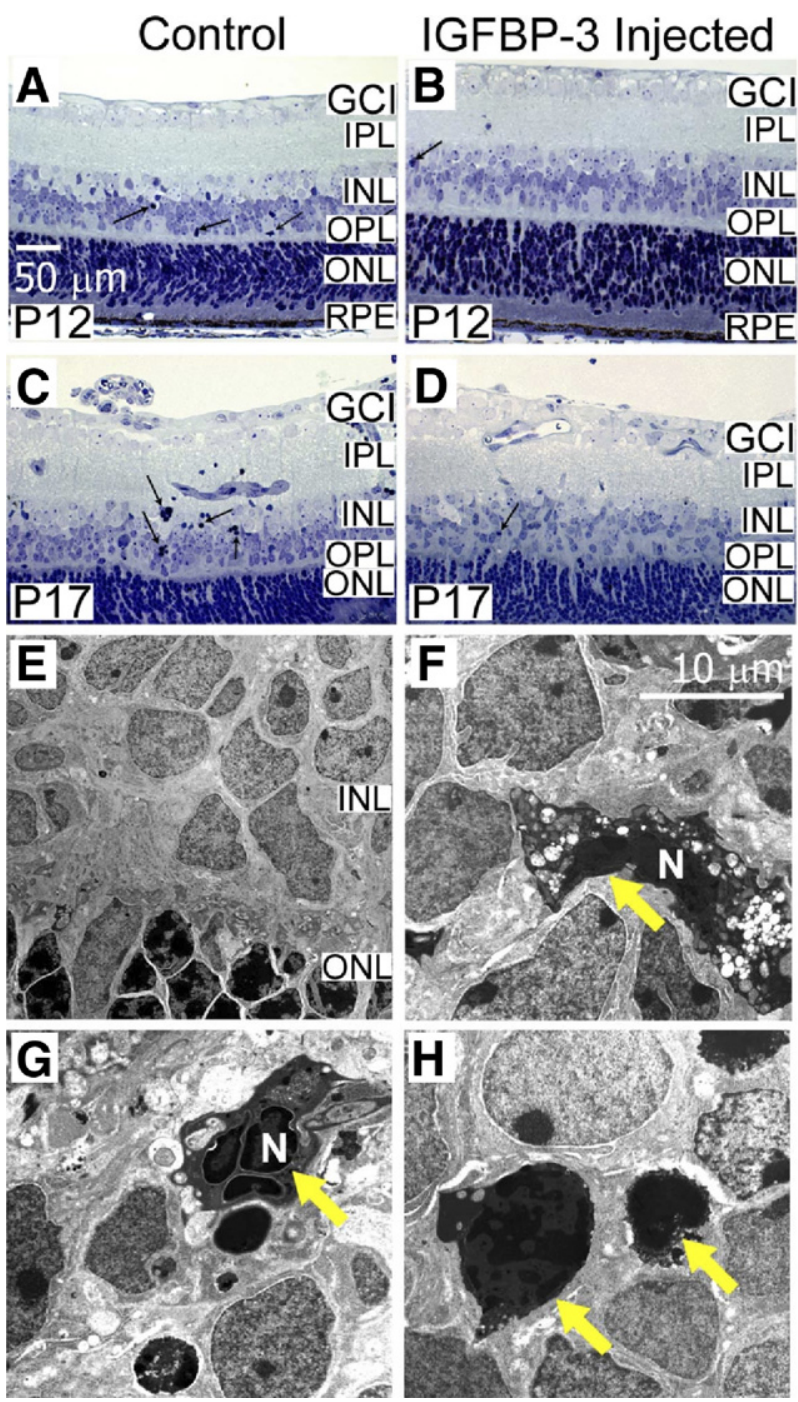

Figure 6. The IGFBP-3 protects neurons from apoptosis during the hypoxic phase of OIR as determined by transmission electron microscopy. A-D. Toluidine blue-stained resin-embedded retinal cross sections: contralateral uninjected eye at P12 (A), IGFBP-3-injected eye at P12 (B), contralateal uninjected eye at P17 (C), and IGFBP-3-injected eye at P17 (D). The IGFBP3 -injected eyes demonstrated reduced cell death, protecting neuronal components of the inner nuclear layer (INL) compared with uninjected control eyes (black arrows denote apoptotic cells in $\mathbf{A}$ and $\mathbf{C}$ ). E: Electron micrograph from an IGFBP-3-injected eye at P17 shows a normal INL and outer nuclear layer (ONL). The uninjected contralateral eye shows various stages of apoptosis in cells of the INL. F: Cell indicated by arrow shows typical "dark cell" change of early apoptosis in neurons with chromatin condensation in nucleus (N) and electron opaque cytoplasm (arrow). G: Cell at a more advanced stage of apoptosis shows nuclear cleavage $(\mathrm{N})$ and opaque shrunken cytoplasm (arrow). H: Hypercondensed apoptotic bodies encased by glial cell cytoplasm (arrows). The scale bar shown in $\mathbf{A}$ applies to A-D. The scale bar shown in $\mathbf{F}$ applies to $\mathbf{E}-\mathbf{H}$.

addition, using triple-marker immunohistochemical analysis with TUNEL, neuronal nuclei marker (NeuN), and $\beta I I I$ tubulin, the percentage of $\mathrm{NeuN}^{+} / \mathrm{TUNEL}^{+}$cells as a percentage of all $\mathrm{NeuN}^{+}$cells was quantified (Figure 7l). The IGFBP-3 was found to cause a significantly lower mean \pm SE proportion of apoptotic neurons $[4.23 \pm 0.50$ (IGFBP-3-injected eye) versus $16.43 \pm 2.78$ (contralateral uninjected control eye)]. Most neuronal apoptosis prevented by IGFBP-3 was found in the inner nuclear layer (Figure $7, \mathrm{~A}-\mathrm{H}$ ) and coincided with reduction of 

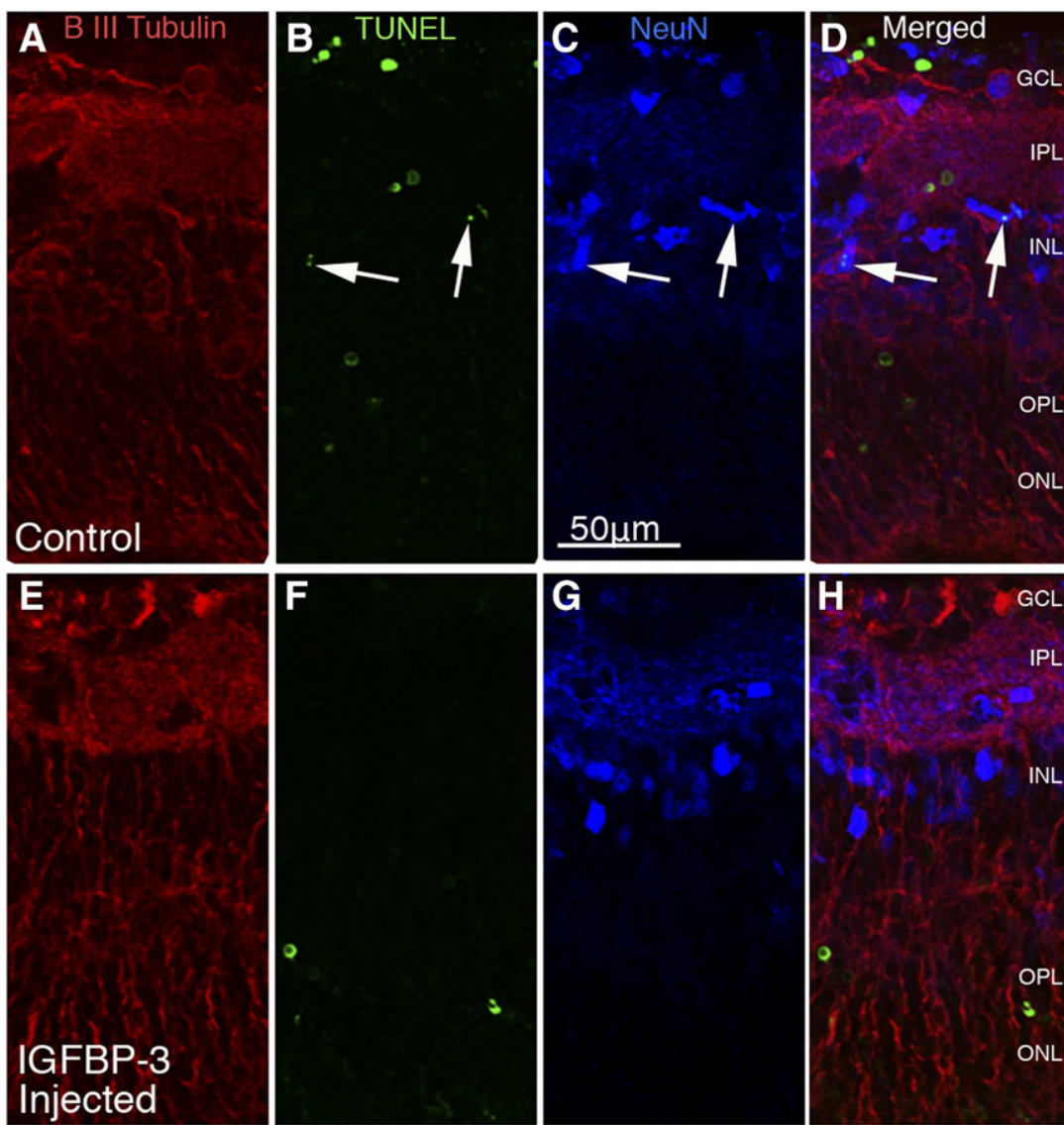
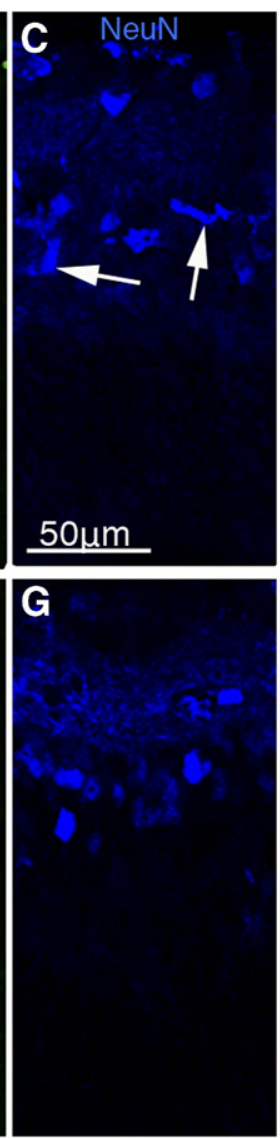

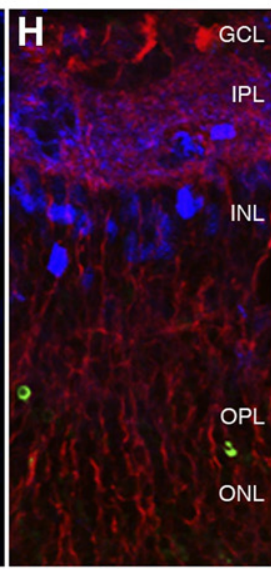

Figure 7. The IGFPB-3 protects neurons from apoptosis during the hypoxic phase of OIR as determined by TUNEL assay. A-H: Retinal sections were triple-labeled with two neuron-specific markers ( $\beta$ III tubulin, red; and NeuN, blue) and combined with TUNEL (green). Compared with contralateral control eyes (A-D), the number of $\mathrm{NeuN}^{+} / \mathrm{TUNEL}^{+}$neurons was markedly reduced in IGFBP-3-overexpressing eyes $(\mathbf{E}-\mathbf{H})$. Arrows indicate representative $\mathrm{NeuN}^{+} / \mathrm{TUNEL}^{+}$neurons that were located predominantly in the inner nuclear layer (INL). I: Quantification of the percentage of $\mathrm{NeuN}^{+} / \mathrm{TUNEL}^{+}$apoptotic neurons against all $\mathrm{NeuN}^{+}$neurons showed a mean \pm SE of $16.43 \% \pm$ $2.78 \%$ in contralateral control eyes versus $4.23 \% \pm$ $0.50 \%$ in IGFBP-3-injected eyes $\left({ }^{* *} P<0.05\right)$. The scale bar shown in $\mathbf{H}$ applies to $\mathbf{A}-\mathbf{H}$. GCL, ganglion cell layer; IPL, inner plexiform layer; OPL, outer plexiform layer; ONL, outer nuclear layer.

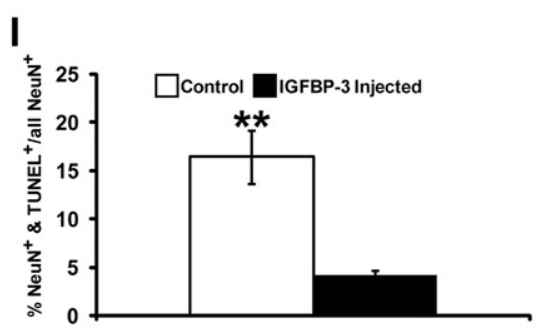

activated microglia/macrophages and reduction of GFAP expression by Müller cells (data not shown) with IGFBP-3 plasmid injection.

\section{Discussion}

In the present study, we show that IGFBP-3 exhibits key cytoprotective effects in the retina. The IGFBP-3 increases pericyte differentiation and ensheathment and decreases apoptosis of pericytes, astrocytes, and retinal neurons while increasing apoptosis of microglia, leading to decreased numbers of activated microglial cells in the ischemic mouse retina.

This is the first report to show that IGFBP-3 reduces the incidence of activated microglia after retinal ischemic injury, which is consistent with recent work by Lee et al. ${ }^{39}$ Using an asthmatic mouse model, they showed that IGFBP-3 could block NF- $\kappa$ B activity in the lungs, supporting its anti-inflammatory ability in another tissue bed. In the OIR mouse model, we show that IGFBP-3 reduces microglial cell activation and infiltration, promotes recruitment of HSCs, and facilitates their differentiation into pericytes and astrocytes while simultaneously preventing their apoptosis. In total, IGFBP-3 enhanced astrocyte and pericyte ensheathment of retinal blood vessels and promoted a more stable vascular bed while also reducing retinal neuronal cell death in the ischemic-injured retina.

The unique properties of IGFBP-3 suggest that IGFBP-3 may have the therapeutic potential to treat or prevent some of the pathologic events associated with retinal ischemia, including edema and impaired perfusion. Because of its vascular stabilizing and cytoprotective nature, IGFBP-3 could have therapeutic use for the treatment of diabetic vascular complications. In diabetic retinopathy, the retinal vasculature is subject to endothelial and pericyte loss, which leads to the hallmark feature of this disease commonly referred to as acellular capillaries. The IGFBP-3 could potentially help by increasing recruitment of progenitor cells to these areas in need of repair while enhancing their differentiation into endothelial cells and pericytes. Pericytes have been specifically implicated in vessel stabilization, modulating endothelial cell proliferation, and preventing vessel regression. ${ }^{22,29,40,41}$ Any intervention that could enhance pericyte recruitment during ischemia would be highly desirable. The ability of IGFBP-3 to modulate inflammation may be of great interest for the treatment of cardiovascular diseases such as atherosclerosis, where inflammation and ischemia have been associated with disease progression.

Although the effects of IGFBP-3 on the vasculature are profound, the mechanism of its effects is not completely understood. The present findings suggest that IGFBP-3 may use multiple mechanisms for its actions depending on the microenvironment. The IGFBP-3 seems to exert its IGF/IGF-IR-independent biological actions through interaction with various binding partners that are present on the cell surface and in cells. The midregion of IGFBP-3, which is the least con- 
served region among IGFBP-1 to IGFBP-6, is responsible for cell surface binding. ${ }^{42,43}$

Although IGFBP-3 binds to the low-density lipoprotein receptor-related protein-1/ $\alpha 2 \mathrm{M}$ receptor, ${ }^{44}$ autocrine motility factor/phosphoglucose isomerase, ${ }^{45}$ caveolin, and the transferrin/transferrin receptor, ${ }^{46}$ the functional significance of these binding partners remains largely unknown. They may result in IGFBP-3 internalization and subsequent biological actions in cytoplasmic and nuclear compartments. As may be the case with the microglial cell apoptosis observed in the present study, IGFBP-3 may induce apoptosis through interaction with nuclear proteins, including retinoid $X$ receptor- $\alpha$, retinoic acid receptor, and Nur77. 47,48 The existence of an IGFBP-3-specific receptor participating in the direct proapoptotic effect of IGFBP-3 in cancer cells was recently identified and found to be a novel cell death receptor. This receptor interacts specifically with IGFBP-3 to activate initiator caspase-8induced apoptosis. ${ }^{49}$

In contrast to the apoptotic effects observed in cancer cells by other researchers ${ }^{50-53}$ and in microglial cells in the present study, we also observed protective effects on endothelium. The IGFBP-3 is expressed by endothelial cells ${ }^{54-56}$ and by endothelial progenitor cells ${ }^{57}$ and has autocrine and paracrine effects. Previously, we showed that scavenger receptor class B, type 1 is the receptor that mediates this vascular protective effect of IGFBP-3. ${ }^{14}$ Scavenger receptor class $B$, type 1 is a high-affinity receptor for high-density lipoprotein and mediates the vascular protective effect of high-density lipoprotein. ${ }^{58}$ Scavenger receptor class $B$, type 1 colocalizes with endothelial nitric oxide synthase in caveolae, and high-density lipoprotein binding to scavenger receptor class $B$, type 1 activates endothelial nitric oxide synthase ${ }^{59,60}$ in an Akt-dependent manner to release nitric oxide. ${ }^{61}$ In the present study, we used an endothelial-specific promoter to direct the enhanced expression of IGFBP-3 by the retinal endothelium. ${ }^{62}$ Under normal physiologic conditions, the entire endothelium is bathed with IGFBP-3 as it circulates in the blood at high nanomolar concentrations. 9,10,63 The approach used in the present study, which targeted IGFBP-3 to the vascular and perivascular regions, represents a physiologically relevant strategy to study this pleotrophic factor as a possible therapeutic.

Although IGFBP-3 primarily circulates in a high-molecular-weight 150-kDa complex with IGFs and the acid-labile subunit produced by the liver, this large complex is held in the circulation and does not readily cross the endothelium. ${ }^{64-66}$ It is unclear what stimuli, apart from vascular injury, cause IGFBP-3 to extravasate and what mechanism(s) allows it to do so.

Granata et $\mathrm{al}^{11}$ showed that IGFBP-3 stimulates IGF-1 release, which, in turn, stimulates sphingosine kinase activity, leading to generation of sphingosine-1-phospate, which is also known to increase nitric oxide generation. We showed previously that IGFBP-3 increases sphingosine kinase mRNA expression in human CD34 ${ }^{+}$ endothelial progenitor cells and microvascular endothe- lial cells ${ }^{14}$; we did not distinguish whether this was a direct IGFBP-3 effect or due to IGFBP-3-mediated IGF-1 release in these cells. However, nitric oxide generation was blocked by the selective sphingosine kinase inhibitor $N, N$-dimethylsphingosine. ${ }^{14}$

In summary, the present study confirms a prominent vasoprotective effect of IGFBP-3 by demonstrating that IGFBP-3 reduces endothelial cell apoptosis and likely decreases the production of pro-inflammatory factors, which can facilitate the local effect of IGFBP-3 to produce nitric oxide and reestablish blood flow. Overexpression of IGFBP-3 by the retinal endothelium restored vascular integrity, protected and stabilized the retinal vasculature after hyperoxia-induced injury, and corrected the retinal morphology of OIR mice to that of a near-normal state. The IGFBP-3 had profound effects on astrocyte and pericyte ensheathment and prevented apoptosis of these vascular cell types and retinal neuronal cells. Thus, IGFBP-3 release by the vasculature after retinal injury may represent part of a physiologic repair mechanism and new therapeutic avenues for ischemic retinopathies.

\section{References}

1. Chen J, Smith LE: Retinopathy of prematurity. Angiogenesis 2007, 10:133-140

2. Mohamed Q, Gillies MC, Wong TY: Management of diabetic retinopathy: a systematic review. JAMA 2007, 298:902-916

3. Aiello LP, Avery RL, Arrigg PG, Keyt BA, Jampel HD, Shah ST, Pasquale LR, Thieme H, Iwamoto MA, Park JE, Nguyen HV, Aiello LM, Ferrara N, King GL: Vascular endothelial growth factor in ocular fluid of patients with diabetic retinopathy and other retinal disorders. N Engl J Med 1994, 331:1480-1487

4. Robinson GS, Pierce EA, Rook SL, Foley E, Webb R, Smith LE: Oligodeoxynucleotides inhibit retinal neovascularization in a murine model of proliferative retinopathy. Proc Natl Acad Sci U S A 1996 , 93:4851-4856

5. Rosenthal R, Wohlleben H, Malek G, Schlichting L, Thieme H, Bowes Rickman C, Strauss O: Insulin-like growth factor-1 contributes to neovascularization in age-related macular degeneration. Biochem Biophys Res Commun 2004, 323:1203-1208

6. Grant MB, Mames RN, Fitzgerald C, Ellis EA, Aboufriekha M, Guy J: Insulin-like growth factor I acts as an angiogenic agent in rabbit cornea and retina: comparative studies with basic fibroblast growth factor. Diabetologia 1993, 36:282-291

7. Grant MB, Mames RN, Fitzgerald C, Ellis EA, Caballero S, Chegini N, Guy J: Insulin-like growth factor I as an angiogenic agent: in vivo and in vitro studies. Ann N Y Acad Sci 1993, 692:230-242

8. Grant MB, Afzal A, Spoerri P, Pan H, Shaw LC, Mames RN: The role of growth factors in the pathogenesis of diabetic retinopathy. Expert Opin Investig Drugs 2004, 13:1275-1293

9. Yamada PM, Lee KW: Perspectives in mammalian IGFBP-3 biology local vs. systemic action. Am J Physiol Cell Physiol 2009, 296:C954976

10. Firth SM, Baxter RC: Cellular actions of the insulin-like growth factor binding proteins. Endocr Rev 2002, 23:824-854

11. Granata R, Trovato L, Lupia E, Sala G, Settanni F, Camussi G, Ghidoni $R$, Ghigo E: Insulin-like growth factor binding protein-3 induces angiogenesis through IGF-I- and SphK1-dependent mechanisms. J Thromb Haemost 2007, 5:835-845

12. Lofqvist C, Chen J, Connor KM, Smith AC, Aderman CM, Liu N, Pintar JE, Ludwig T, Hellstrom A, Smith LE: IGFBP3 suppresses retinopathy through suppression of oxygen-induced vessel loss and promotion of vascular regrowth. Proc Natl Acad Sci U S A 2007, 104:10589-10594

13. Chang KH, Chan-Ling T, McFarland EL, Afzal A, Pan H, Baxter LC, Shaw LC, Caballero S, Sengupta N, Li Calzi S, Sullivan SM, Grant MB: IGF binding protein-3 regulates hematopoietic stem cell and endo- 
thelial precursor cell function during vascular development. Proc Nat Acad Sci U S A 2007, 104:10595-10600

14. Kielczewski JL, Jarajapu YP, McFarland EL, Cai J, Afzal A, Li Calzi S, Chang KH, Lydic T, Shaw LC, Busik J, Hughes J, Cardounel AJ, Wilson K, Lyons TJ, Boulton ME, Mames RN, Chan-Ling T, Grant MB: Insulin-like growth factor binding protein-3 mediates vascular repair by enhancing nitric oxide generation. Circ Res 2009, 105:897-905

15. Annabi B, Lee YT, Turcotte S, Naud E, Desrosiers RR, Champagne M, Eliopoulos N, Galipeau J, Beliveau R: Hypoxia promotes murine bone-marrow-derived stromal cell migration and tube formation. Stem Cells 2003, 21:337-347

16. Grant MB, May WS, Caballero S, Brown GA, Guthrie SM, Mames RN Byrne BJ, Vaught T, Spoerri PE, Peck AB, Scott EW: Adult hematopoietic stem cells provide functional hemangioblast activity during retinal neovascularization. Nat Med 2002, 8:607-612

17. Sengupta N, Caballero S, Mames RN, Butler JM, Scott EW, Grant MB: The role of adult bone marrow-derived stem cells in choroidal neovascularization. Invest Ophthalmol Vis Sci 2003, 44:4908-4913

18. Sengupta N, Caballero S, Mames RN, Timmers AM, Saban D, Grant MB: Preventing stem cell incorporation into choroidal neovascularization by targeting homing and attachment factors. Invest Ophthalmol Vis Sci 2005, 46:343-348

19. Shaw LC, Pan H, Afzal A, Calzi SL, Spoerri PE, Sullivan SM, Grant MB: Proliferating endothelial cell-specific expression of IGF-I receptor ribozyme inhibits retinal neovascularization. Gene Ther 2006, 13:752760

20. Smith LE, Wesolowski E, McLellan A, Kostyk SK, D'Amato R, Sullivan R, D'Amore PA: Oxygen-induced retinopathy in the mouse. Invest Ophthalmol Vis Sci 1994, 35:101-111

21. Gardiner TA, Stitt AW, Anderson HR, Archer DB: Selective loss of vascular smooth muscle cells in the retinal microcirculation of diabetic dogs. Br J Ophthalmol 1994, 78:54-60

22. Hughes S, Chan-Ling T: Characterization of smooth muscle cell and pericyte differentiation in the rat retina in vivo. Invest Ophthalmol Vis Sci 2004, 45:2795-2806

23. Chan-Ling T, Chu Y, Baxter L, Weible li M, Hughes S: In vivo characterization of astrocyte precursor cells (APCs) and astrocytes in developing rat retinae: differentiation, proliferation, and apoptosis. Glia 2009, 57:39-53

24. Ozerdem U, Grako KA, Dahlin-Huppe K, Monosov E, Stallcup WB: NG2 proteoglycan is expressed exclusively by mural cells during vascular morphogenesis. Dev Dyn 2001, 222:218-227

25. Medana IM, Hunt NH, Chan-Ling T: Early activation of microglia in the pathogenesis of fatal murine cerebral malaria. Glia 1997, 19:91-103

26. Chan-Ling T, Halasz P, Stone J: Development of retinal vasculature in the cat: processes and mechanisms. Current Eye Res 1990, 9:459478

27. Htain WW, Leong SK, Ling EA: A comparative Mac-1 immunocytochemical and lectin histochemical study of microglial cells in the normal and athymic mice. Glia 1994, 12:44-51

28. Maddox DE, Shibata S, Goldstein IJ: Stimulated macrophages express a new glycoprotein receptor reactive with Griffonia simplicifolia I-B4 isolectin, Proc Natl Acad Sci U S A 1982, 79:166-170

29. Hughes $S$, Chan-Ling T: Roles of endothelial cell migration and apoptosis in vascular remodelling during development of the central nervous system. Microcirculation 2000, 7:317-333

30. Chan-Ling T, Baxter L, Weible II MW, Hughes S: In vivo characterization of astrocyte precursor cells (APCs) and astrocytes in developing rat retinae; differentiation, proliferation and apoptosis. Glia 2009, 57:39-53

31. Chan-Ling T, Page MP, Gardiner T, Baxter L, Rosinova E, Hughes S: Desmin ensheathment ratio as an indicator of vessel stability: evidence in normal development and in retinopathy of prematurity. Am J Pathol 2004, 165:1301-1313

32. Ritter MR, Banin E, Moreno SK, Aguilar E, Dorrell MI, Friedlander M: Myeloid progenitors differentiate into microglia and promote vascular repair in a model of ischemic retinopathy. J Clin Invest 2006, 116: 3266-3276

33. Otani A, Kinder K, Ewalt K, Otero FJ, Schimmel P, Friedlander M: Bone marrow-derived stem cells target retinal astrocytes and can promote or inhibit retinal angiogenesis. Nat Med 2002, 8:1004-1010

34. Friedlander M, Dorrell MI, Ritter MR, Marchetti V, Moreno SK, El-Kalay M, Bird AC, Banin E, Aguilar E: Progenitor cells and retinal angiogenesis. Angiogenesis 2007, 10:89-101
35. Barber CL, Iruela-Arispe ML: The ever-elusive endothelial progenitor cell: identities, functions and clinical implications. Pediatr Res 2006, 59:26R-32R

36. Chan-Ling T, Baxter L, Afzal A, Sengupta N, Caballero S, Rosinova E, Grant MB: Hematopoietic stem cells provide repair functions after laser-induced Bruch's membrane rupture model of choroidal neovascularisation. Am J Pathol 2006, 168:1031-1044

37. Davies MH, Eubanks JP, Powers MR: Microglia and macrophages are increased in response to ischemia-induced retinopathy in the mouse retina. Mol Vis 2006, 12:467-477

38. Kramerov AA, Saghizadeh M, Pan H, Kabosova A, Montenarh M, Ahmed K, Penn JS, Chan CK, Hinton DR, Grant MB, Ljubimov AV: Expression of protein kinase CK2 in astroglial cells of normal and neovascularized retina. Am J Pathol 2006, 168:1722-1736

39. Lee YC, Jogie-Brahim S, Harada A, Lee DY, Han J, Murphy LJ, Oh Y Inhibitory role of IGFBP-3 in the pathogenesis of asthma. Endo Rev 2010, 31:S1036

40. Benjamin LE, Hemo I, Keshet E: A plasticity window for blood vessel remodelling is defined by pericyte coverage of the preformed endothelial network and is regulated by PDGF-B and VEGF. Development 1998, 125:1591-1598

41. Darland DC, D'Amore PA: Blood vessel maturation: vascular development comes of age. J Clin Invest 1999, 103:157-158

42. Oh Y, Muller HL, Lee DY, Fielder PJ, Rosenfeld RG: Characterization of the affinities of insulin-like growth factor (IGF)-binding proteins 1-4 for IGF-I, IGF-II, IGF-I/insulin hybrid, and IGF-I analogs. Endocrinology 1993, 132:1337-1344

43. Yamanaka Y, Fowlkes JL, Wilson EM, Rosenfeld RG, Oh Y: Characterization of insulin-like growth factor binding protein-3 (IGFBP-3) binding to human breast cancer cells: kinetics of IGFBP-3 binding and identification of receptor binding domain on the IGFBP-3 molecule. Endocrinology 1999, 140:1319-1328

44. Huang SS, Ling TY, Tseng WF, Huang YH, Tang FM, Leal SM, Huang JS: Cellular growth inhibition by IGFBP-3 and TGF- $\beta 1$ requires LRP-1. FASEB J 2003, 17:2068-2081

45. Mishra S, Raz A, Murphy LJ: Insulin-like growth factor binding protein-3 interacts with autocrine motility factor/phosphoglucose isomerase (AMF/PGI) and inhibits the AMF/PGI function. Cancer Res 2004, 64:2516-2522

46. Weinzimer SA, Gibson TB, Collett-Solberg PF, Khare A, Liu B, Cohen $P$ : Transferrin is an insulin-like growth factor-binding protein-3 binding protein. J Clin Endocrinol Metab 2001, 86:1806-1813

47. Liu B, Lee KW, Li H, Ma L, Lin GL, Chandraratna RA, Cohen P: Combination therapy of insulin-like growth factor binding protein-3 and retinoid $X$ receptor ligands synergize on prostate cancer cell apoptosis in vitro and in vivo. Clin Cancer Res 2005, 11:4851-4856

48. Liu B, Lee HY, Weinzimer SA, Powell DR, Clifford JL, Kurie JM, Cohen $P$ : Direct functional interactions between insulin-like growth factorbinding protein-3 and retinoid $X$ receptor- $\alpha$ regulate transcriptional signaling and apoptosis. J Biol Chem 2000, 275:33607-33613

49. Ingermann AR, Yang YF, Paisley TE, Han J, Mikami A, Garza AE, Mohanraj L, Fan L, Idowu M, Ware JL, Kim HS, Lee DY, Oh Y: Identification of a novel cell death receptor mediating IGFBP-3-induced antitumor effects in breast cancer and prostate cancer. J Biol Chem 2010, 285:30233-30246

50. Gill ZP, Perks CM, Newcomb PV, Holly JM: Insulin-like growth factorbinding protein (IGFBP-3) predisposes breast cancer cells to programmed cell death in a non-IGF-dependent manner. J Biol Chem 1997, 272:25602-25607

51. Baxter RC: Signalling pathways involved in antiproliferative effects of IGFBP-3: a review. Mol Pathol 2001, 54:145-148

52. Mishra S, Murphy LJ: The effects of insulin-like growth factor binding protein-3 (IGFBP-3) on T47D breast cancer cells enriched for IGFBP-3 binding sites. Mol Cell Biochem 2004, 267:83-89

53. Butt AJ, Firth SM, King MA, Baxter RC: Insulin-like growth factorbinding protein-3 modulates expression of Bax and $\mathrm{Bcl}-2$ and potentiates p53-independent radiation-induced apoptosis in human breast cancer cells. J Biol Chem 2000, 275:39174-39181

54. Chin E, Zhou J, Dai J, Baxter RC, Bondy CA: Cellular localization and regulation of gene expression for components of the insulin-like growth factor ternary binding protein complex. Endocrinology 1994, 134:2498-2504

55. Booth BA, Boes M, Andress DL, Dake BL, Kiefer MC, Maack C, Linhardt RJ, Bar K, Caldwell EE, Weiler J: IGFBP-3 and IGFBP-5 
association with endothelial cells: role of C-terminal heparin binding domain. Growth Regul 1995, 5:1-17

56. Granata R, Trovato L, Garbarino G, Taliano M, Ponti R, Sala G, Ghidoni R, Ghigo E: Dual effects of IGFBP-3 on endothelial cell apoptosis and survival: involvement of the sphingolipid signaling pathways. FASEB J 2004, 18:1456-1458

57. Liu LQ, Sposato M, Liu HY, Vaudrain T, Shi MJ, Rider K, Stevens Z, Visser J, Deng HK, Kraus M: Functional cloning of IGFBP-3 from human microvascular endothelial cells reveals its novel role in promoting proliferation of primitive $\mathrm{CD} 34^{+} \mathrm{CD} 38^{-}$hematopoietic cells in vitro. Oncol Res 2003, 13:359-371

58. Norata GD, Catapano AL: Molecular mechanisms responsible for the antiinflammatory and protective effect of $\mathrm{HDL}$ on the endothelium. Vasc Health Risk Manag 2005, 1:119-129

59. Yuhanna IS, Zhu Y, Cox BE, Hahner LD, Osborne-Lawrence S, Lu P, Marcel YL, Anderson RG, Mendelsohn ME, Hobbs HH, Shaul PW: High-density lipoprotein binding to scavenger receptor-BI activates endothelial nitric oxide synthase. Nat Med 2001, 7:853-857

60. Mineo C, Shaul PW: HDL stimulation of endothelial nitric oxide synthase: a novel mechanism of HDL action. Trends Cardiovasc Med 2003, 13:226-231
61. Mineo C, Yuhanna IS, Quon MJ, Shaul PW: High density lipoproteininduced endothelial nitric-oxide synthase activation is mediated by Akt and MAP kinases. J Biol Chem 2003, 278:9142-9149

62. Spoerri PE, Caballero S, Wilson SH, Shaw LC, Grant MB: Expression of IGFBP-3 by human retinal endothelial cell cultures: IGFBP-3 involvement in growth inhibition and apoptosis. Invest Ophthalmol Vis Sci 2003, 44:365-369

63. Jogie-Brahim S, Feldman D, Oh Y: Unraveling insulin-like growth factor binding protein-3 actions in human disease. Endocr Rev 2009, 30:417-437

64. Keku TO, Sandler RS, Simmons JG, Galanko J, Woosley JT, Proffitt M, Omofoye O, McDoom M, Lund PK: Local IGFBP-3 mRNA expression, apoptosis and risk of colorectal adenomas. BMC Cancer 2008, 8:143

65. Lee DY: Identification of insulin-like growth factor (IGF)-I and IGFbinding protein in chylous ascites. J Korean Med Sci 1998, 13:17-20

66. Lemmey AB, Glassford J, Flick-Smith HC, Holly JM, Pell JM: Differential regulation of tissue insulin-like growth factor-binding protein (IGFBP)-3: IGF-I and IGF type 1 receptor mRNA levels, and serum IGF-I and IGFBP concentrations by growth hormone and IGF-I. J Endocrinol 1997, 154:319-328 